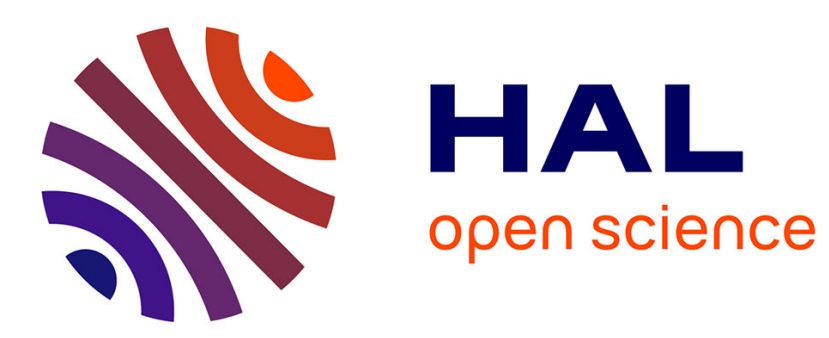

\title{
THRESHOLD IONISATION BY ELECTRON IMPACT
}

\author{
H. Lebius, B. Huber, H. Koslowski, K. Wiesemann
}

\section{To cite this version:}

H. Lebius, B. Huber, H. Koslowski, K. Wiesemann. THRESHOLD IONISATION BY ELECTRON IMPACT. Journal de Physique Colloques, 1989, 50 (C1), pp.C1-399-C1-403. 10.1051/jphyscol:1989147 . jpa-00229345

\section{HAL Id: jpa-00229345 https://hal.science/jpa-00229345}

Submitted on 1 Jan 1989

HAL is a multi-disciplinary open access archive for the deposit and dissemination of scientific research documents, whether they are published or not. The documents may come from teaching and research institutions in France or abroad, or from public or private research centers.
L'archive ouverte pluridisciplinaire HAL, est destinée au dépôt et à la diffusion de documents scientifiques de niveau recherche, publiés ou non, émanant des établissements d'enseignement et de recherche français ou étrangers, des laboratoires publics ou privés. 
JOURNAL DE PHYSIQUE

Colloque $\mathrm{C} 1$, supplément au $\mathrm{n}^{\circ} 1$, Tome 50 , janvier 1989

C1-399

THRESHOLD IONISATION BY ELECTRON IMPACT

H. LEBIUS, B.A. HUBER, H.R. KOSLOWSKI and $\mathrm{K}$. WIESEMANN

Institut für Experimentalphysik AG II, Ruhr-Universität, D-4630 Bochum, F.R.G.

\section{Abstract}

Multiple ionisation of rare gas atoms by electron impact has been studied experimentally close to the ionisation thresholds. In this energy range the cross sections are described by threshold laws, yielding resonable agreement with theory for He and $\mathrm{Ne}$. In the heavier targets the exponent value is found to be smaller than predicted and the results can be interpreted in terms of a pure statistical theory.

\section{I) Introduction}

The electron impact ionisation process close to the ionisation threshold represents an interesting phenomenon which has attracted much interest during recent years. It is characterized by a long range coulomb interaction between several particles, which can be hardly treated quantum mechanically over large internuclear distances.

Thus, the first description dating to 1953 by Wannier and deriving a threshold law mainly follows arguments of classical mechanics /1/ yielding the famous relation

$$
\sigma \sim E^{1.127} \text {. }
$$

Here $E$ represents the amount of energy by which the total energy of the system exceeds the ionisation energy of the atom. This relation holds only for small values of $E$ and describes the escape of two electrons, i.e. the process of photo-double detachment of negative ions and single ionisation of atoms by electron impact.

An extension to the case of multiple ionisation was made by Wannier in $1955 / 2 /$ using simple phase space arguments. The q-fold ionisation cross section for electron-atom collisions is described close to the ionisation threshold by

$$
\sigma \sim\left(E_{1}-E_{\mathrm{thr}}\right)^{k} \text { with } k \approx \mathrm{q}
$$

whereby $E_{1}$ represents the electron energy and $E_{\mathrm{th}}$ the threshold energy for direct ionisation.

Meanwhile further classical, semiclassical or quantum-mechanical calculations have been performed to study the multiple-electron escape process including electron correlation effects /3-9/. In general equation (2) is confirmed, however, the exponent $k$ should be slightly larger than the charge $q$ of the produced ion. For double, triple and fourfold ionisation of neutral atoms by electron impact the ratio $k / q$ is expected to be $1.135,1.175$ and $>1.175$. 
Up to now experiments have been mainly concerned with the single ionisation process confirming the Wannier exponent of 1.127 . However, in the case of multiple ionisation the number of experiments is very small. Therefore, we analysed the threshold behavior of the multiple ionisation cross section in different rare gases and studied the importance of electron correlation effects for different numbers of electrons involved.

\section{II) Experiment}

The apparatus being used in this experiment is shown in figure 1 . Within an electron impact ion source multiply charged ions are produced under single collision conditions. The pulsed electron beam is emitted

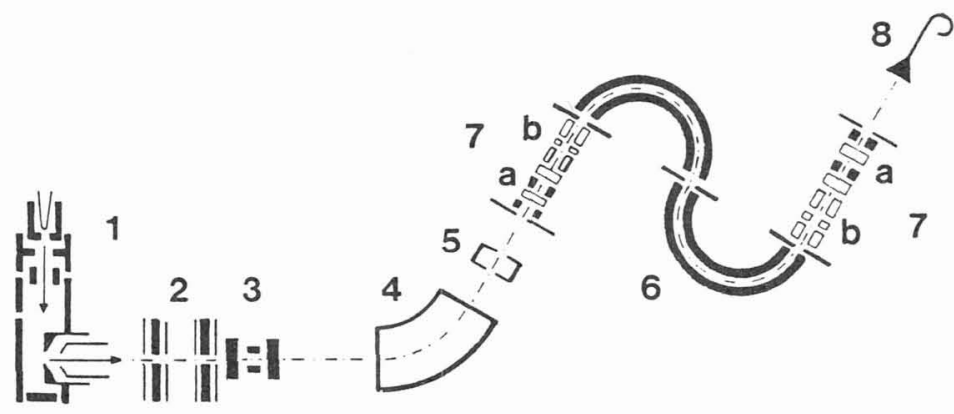

Figure 1 Experimental setup: 1-ion source, 2-electrostatic lenses, 3 and 7 a-deflection plates, 4-magnetic sector field, 5-collision chamber, 6-energy analyser, 7b-zoom lenses, 8-channeltron

from an equipotential cathode with an energetic halfwidth of about 500 meV. The ions are softly extracted and focused onto the entrance aperture of a magnetic sector field. After mass and charge state analysis the ions pass a collision chamber, some ion optics, an energy filter and finally are detected with the aid of a channeltron.

The collision chamber and the energy analyser may be used in order to perform translational energy spectroscopy; by this means the internal states of the produced ions can be determined and stateselective cross sections can be measured /10/. The results presented below have been obtained without an internal state analysis.

During the experiment all voltages are kept constant with the exception of the electron acceleration voltage and the voltage of the electron lens in the ion source. For further details see e.g. ref. $111 /$.

\section{III) Results and discussion}

Cross sections for multiple ionisation of $\mathrm{He}, \mathrm{Ne}, \mathrm{Kr}$ and $\mathrm{Xe}$ by electron impact have been measured and analysed in the energy range close to the ionisation threshold. The charge states of the produced ions vary from one to four. As far as the evaluated range of electron energies lies below the threshold for the first excited state (neglecting the spin-orbit splitting of the ground state) the results represent state-selective cross sections.

Figure 2 shows the threshold region of the double ionisation cross section in He. In the energy range up to $5 \mathrm{ev}$ above threshold the experimental data can be described quite well by a threshold law with 
an exponent of $K=2.14$, which is in very good agreement with theory considering the total error of $K$ which amounts to 10\%. Previous measurements of Brion and Thomas /12/ yielded as a best fit a quadratic dependence of $\sigma$ on $E$. This gives a less good agreement with our measurements.

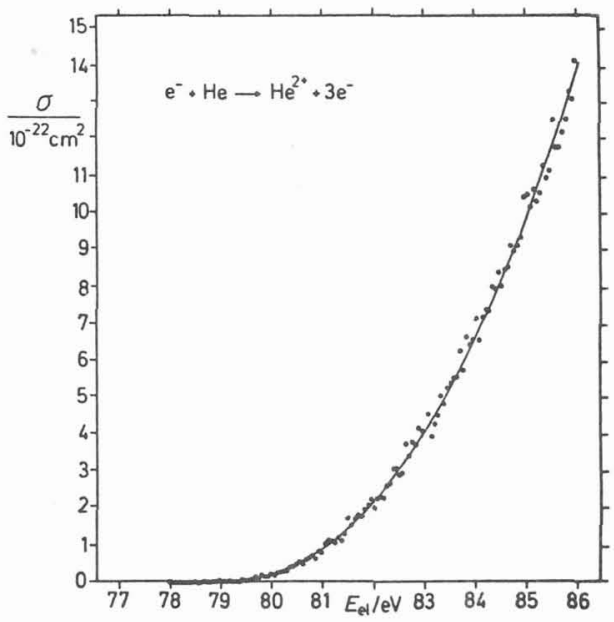

Eigure 2 Partial double ionisation cross section for He. $E_{\mathrm{hr}}=79$ ev; the full curve represents a fit with $K=2.14$.

The variation of the exponent with the charge state $q$ of the produced ions becomes very obvious in figure 3, where cross sections for single, double and triple ionisation of Ne are presented. Whereas for the single ionisation the cross section rises nearly linear with $E$, in the case of multiple ionisation the curvature close to the ionisation threshold strongly increases with increasing $q$ as predicted by theory. A detailed analysis yields exponent values of $K_{1}=1.06, K_{2}$ $=2.04$ and $k_{i 3}=3.16 ;$ all values beeing larger than $q$ and agreeing with the theoretical predictions within the obtaine 1 error bounds.

Similar experiments have been performed with $\mathrm{Kr}$ and $\mathrm{Xe}$ as target gases, whereby $\mathrm{Kr}$ ions in charge states 2 and 3 and $X e$ ions in charge states 2 to 4 have been measured. Surprisingly, in both cases the $K$ values are smaller than the produced charge state $q$, the deviations being larger than the experimental error in several cases.

An overview on the exponent values determined in various systems is given in table 1 , together with predictions of the above mentioned theories and with results of a pure statistical calculation according to the statistical energy deposition model (SED) of Russek /13/.

The results for $\mathrm{Kr}$ and $\mathrm{Xe}$ with $\mathrm{q}=2$ and 3 can be reproduced quite well by the statistical energy deposition model as can be seen from table 1. The theoretical values are smaller than $q$ as we consider a finite range of $E$ above threshold (a few eV); only in the case $E \rightarrow->0$ one might expect $K$ to be equal to $q$. Within this model the surplus energy $E$ is distributed statistically among the escaping electrons and thus no restrictions with respect to favourable geometries in the escaping process are considered in the sED model. 


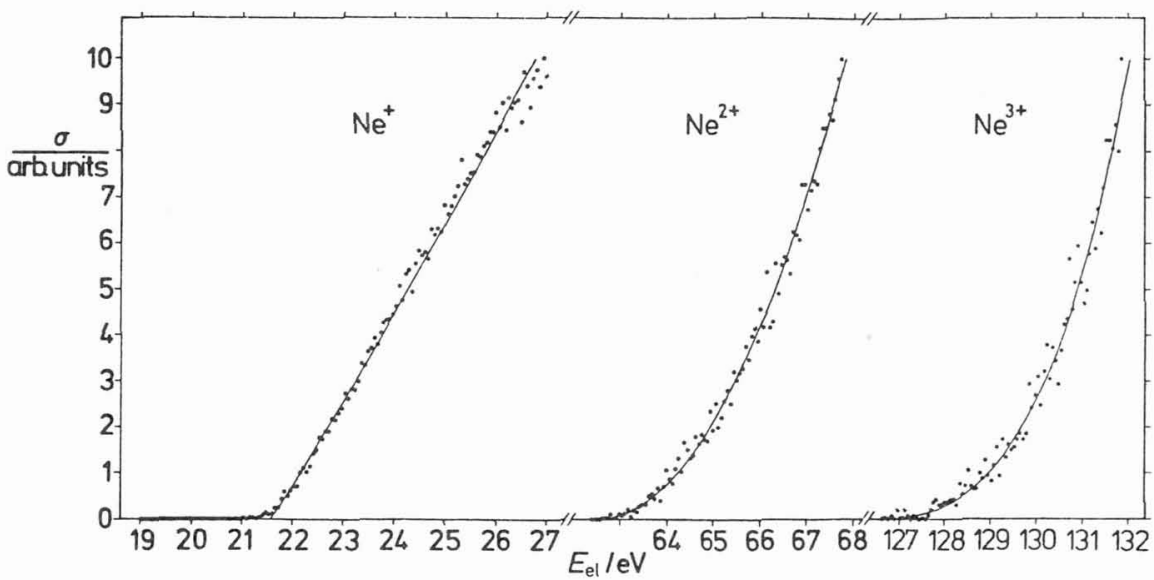

Figure 3 Partial cross sections for single, double and triple ionisation of $\mathrm{Ne}$ atoms by electron impact (one arbitrary unit corresponds $5 * 10^{-19} \mathrm{~cm}^{2}, 4.5 * 10^{-22} \mathrm{~cm}^{2}$ and $4.8 * 10^{-24} \mathrm{~cm}^{2}$ for $\mathrm{Ne}^{+}, \mathrm{Ne}^{2+}$ and $\mathrm{Ne}^{3+}$, respectively).

Table 1 Threshold law exponents for various single and multiple ionisation processes.

\begin{tabular}{|c|c|c|c|c|c|c|}
\hline $\begin{array}{l}\text { produced } \\
\text { ion }\end{array}$ & $\begin{array}{l}\text { exper } \\
x\end{array}$ & $\Delta k$ & $E$ a $x / e V$ & theory & SED & \\
\hline $\begin{array}{l}\mathrm{He}^{+} \\
\mathrm{He}^{2+}\end{array}$ & $\begin{array}{l}1.15 \\
2.14\end{array}$ & $\begin{array}{l}0.06 \\
0.21\end{array}$ & $\begin{array}{l}6.0 \\
5.5\end{array}$ & $\begin{array}{l}1.127 \\
2.270\end{array}$ & & \\
\hline $\begin{array}{l}\mathrm{Ne}^{+} \\
\mathrm{Ne}^{2+} \\
\mathrm{Ne}^{3+} \\
\mathrm{Ne}^{4+}\end{array}$ & $\begin{array}{l}1.06 \\
2.04 \\
3.16 \\
4.15\end{array}$ & $\begin{array}{l}0.05 \\
0.14 \\
0.32 \\
0.63\end{array}$ & $\begin{array}{l}5.3 \\
4.5 \\
4.8 \\
4.5\end{array}$ & $\begin{array}{l}1.127 \\
2.270 \\
3.525 \\
>4.7\end{array}$ & & \\
\hline $\begin{array}{l}\mathrm{K} \mathbf{r}^{2+} \\
\mathrm{K} \mathbf{r}^{3+}\end{array}$ & $\begin{array}{l}1.97 \\
2.63\end{array}$ & $\begin{array}{l}0.1 \\
0.3\end{array}$ & $\begin{array}{l}4.6 \\
6.5\end{array}$ & $\begin{array}{l}2.270 \\
3.525\end{array}$ & $\begin{array}{l}1.88 \\
2.85\end{array}$ & \\
\hline $\begin{array}{l}X e^{2+} \\
X e^{3+} \\
X e^{4+}\end{array}$ & $\begin{array}{l}1.85 \\
2.80 \\
2.6\end{array}$ & $\begin{array}{l}0.1 \\
0.1\end{array}$ & $\begin{array}{l}5.7 \\
6.6\end{array}$ & $\begin{array}{l}2.270 \\
3.525 \\
>4.7\end{array}$ & $\begin{array}{l}1.83 \\
2.82 \\
3.7\end{array}$ & $(2.8)$ \\
\hline
\end{tabular}

The four-fold ionisation of $\mathrm{Xe}$ atoms seems to be a special case, as the experimental $k$ value is found to be well below the SED result. However, if we assume that in a first step an autoionising state of $\mathrm{Xe}^{3+}$ is formed decaying by an Auger process into $\mathrm{Xe}^{4+}$, we find good agreement with the SED predictions. A comparison is made in figure 4 , where $K$ has been determined by fitting procedures overlaping a wider range of $E_{\mathrm{max}}$. The dotted curves represent the result for a primary process where three electrons are emitted in addition to the incoming electron. 


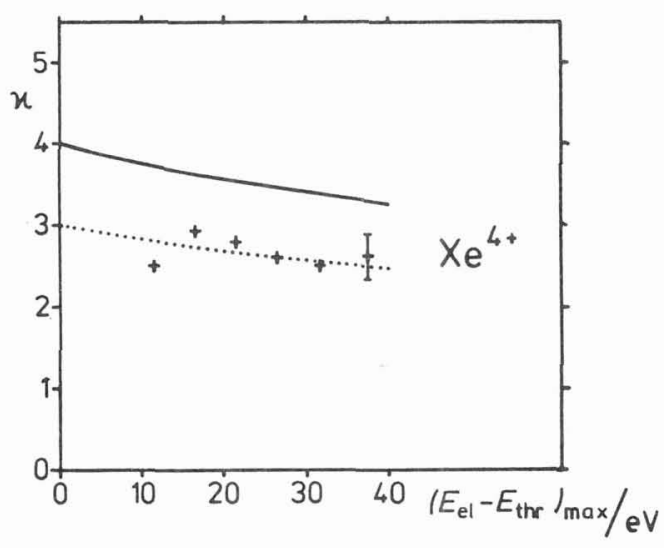
Figure 4: exponent value $k$ versus the length of the fitting interval above threshold in the case of $\mathrm{Xe}^{4+}$. + experimental values; - SED result for a direct process; ... SED result assuming an intermediate autoionising $\mathrm{Xe}^{3+}$ state.

Sumarizing we may say, that in the case of few electron systems like He good agreement is found with theories which include the electron correlation effects. If we increase the number of electrons in the system $k$ becomes smaller and the process can be described more or less as a statistical one. Furthermore, the influence of autoionising states, which are located close to the ionisation threshold, becomes more important for heavier rare gas atoms.

\section{References}

/1/ Wannier, G.H., Phys. Rev. 90 (1953) 817

/2/ Wannier, G.H., Phys. Rev. 100 (1955) 1180

$13 /$ Klar, H. and Schlecht, W. J. Phys. B10 (1976) 1699

/4/ Grujic, P., J. Phys. B15 (1982) 1913

15/ Grujic, P., J. Phys. B16 (1983) 2567

/6/ Grujic, P.., Phys. Lett. 96A (1983) 233

/7/ Read, F.H. in 'Electron Impact Ionization', eds. T.D. Märk and G.H. Dunn, Springer Verlag, Wien New York (1985)

/8/ Rau, A.R.P., Comments At. Mol. Phys. 14 (1984) 285

19/ Grujic, P., Comments At. Mol. Phys. 18

$110 /$ Huber, B.A., Comments At. Mo1. Phys. $\underline{21}$ (1987) 15

/11/ Koslowski, H.R., Binder, J., Huber, B.A. and Wiesemann, K., J. Phys. B20 (1987) 5903

112/ Brion, C.E. and Thomas, G.E., J. Mass spectr. Ion Phys. 1 (1968) 25

/13/ Russek, A. Phys. Rev. 132 (1963) 246 